\title{
Do position and size matter? An analysis of cage and placement variables for optimum lordosis in PLIF reconstruction
}

\author{
Priyan R. Landham ${ }^{1}$ - Angus S. Don ${ }^{2} \cdot$ Peter A. Robertson $^{2}$ (B)
}

Received: 6 May 2016/Revised: 16 May 2017/Accepted: 5 June 2017/Published online: 15 June 2017

(c) The Author(s) 2017. This article is an open access publication

\begin{abstract}
Purpose To examine monosegmental lordosis after posterior lumbar interbody fusion (PLIF) surgery and relate lordosis to cage size, shape, and placement.

Methods Eighty-three consecutive patients underwent single-level PLIF with paired identical lordotic cages involving a wide decompression and bilateral facetectomies. Cage parameters relating to size (height, lordosis, and length) and placement (expressed as a ratio relative to the length of the inferior vertebral endplate) were recorded. Centre point ratio (CPR) was the distance to the centre of both cages and indicated mean position of both cages. Posterior gap ratio (PGR) was the distance to the most posterior cage and indicated position and cage length indirectly. Relationships between lordosis and cage parameters were explored.

Results Mean lordosis increased by $5.98^{\circ}\left(\operatorname{SD~} 6.86^{\circ}\right)$. The cages used varied in length from 20 to $27 \mathrm{~mm}$, in lordosis from $10^{\circ}$ to $18^{\circ}$, and in anterior cage height from 10 to $17 \mathrm{~mm}$. The mean cage placement as determined by CPR was 0.54 and by PGR was 0.16 . The significant correlations were: both CPR and PGR with lordosis gain at surgery ( $r=0.597$ and 0.537 , respectively, $p<0.001$ both), cage lordosis with the final lordosis $(r=0.234, p<0.05)$, and anterior cage height was negatively correlated with a change in lordosis $(r=-0.297, p<0.01)$.
\end{abstract}

Peter A. Robertson

p.a.robertson@xtra.co.nz

1 Department of Orthopaedic Surgery, Southmead Hospital, Bristol, UK

2 Department of Orthopaedic Surgery, Auckland City Hospital, Auckland, New Zealand
Conclusion Cage size, shape, and position, in addition to surgical technique, determine lordosis during PLIF surgery. Anterior placement with sufficient "clear space" behind the cages is recommended. In addition, cages should be of moderate height and length, so that they act as an effective pivot for lordosis.

Keywords Lumbar · Fusion · Lordosis · Cage · Position

\section{Introduction}

There is increasing recognition of the need for anatomical reconstruction of sagittal alignment in spinal fusion operations. Recreating the patient's lumbar sagittal alignment reduces the need for adjacent non-fused segments of the spine to compensate for any sagittal deformity at the site of fusion. The importance of normal sagittal alignment has been increasingly recognised in multi-segmental fusions for spinal deformity [1-3]. With increasing focus on patient-related outcomes, there is mounting evidence that optimum sagittal alignment in lumbar fusion is associated with improved outcomes across differing pathologies [1, 4-9], reduced post-surgical pain [1-3, 5-8, 10-13], reduced adjacent segment degeneration [4, 5, 7, 9-14], and reduced revision rates $[1-5,7,9-11,13,15-18]$.

The majority of indications for lumbar spinal fusion are associated with regional hypo-lordosis. In the normal lumbar spine, where the pelvic morphology is associated with varying degrees of lordosis $[1-3,5-7,12]$, the greatest contribution to the lordosis is between L4 and S1. While the trapezoidal sagittal shape of the L5 vertebra does contribute to the lordosis in the lower lumbar spine, the major contributor to lordosis is the lordotic angulation of the L4/5 and L5/S1 disc spaces, where approximately $12^{\circ}$ 
and $15^{\circ}$ of lordosis occur at each level, respectively $[1-3,5,7,10-13,19]$. Pathological processes that result in disc space narrowing will reduce lordosis. Failure to correct this pre-operative sagittal plane deformity will compromise results in both the short and long terms $[5,7,10,11,13]$.

Modern posterior lumbar interbody fusion (PLIF) is a recognised technique for achieving lumbar fusion [20-22]. It involves the insertion of paired lordotic cages into the intervertebral disc space combined with posterior pedicle screw and rod instrumentation. The purpose of the interbody cage is to recreate the disc space and restore the intervertebral lordosis and foraminal height while providing an area for fusion.

It is interesting, however, that with interbody reconstruction, the degree of lordosis recreation can be limited and may not recreate normality $[1-3,16-18]-$ a concern when we recognise the significant lordosis in the normal L4/5 and L5/S1 discs [1, 5, 7, 12].

Applying the principles of deformity correction requires anterior column distraction and posterior shortening to achieve increased lordosis. Once the sagittal plane deformity becomes correctable, the shape, size, and placement of implants may then influence the reconstructed alignment in the sagittal plane.

The aim of this study is to investigate both cage variables and cage position reflecting surgical technique, to assess their influence on monosegmental lordosis in PLIF reconstruction.

\section{Methods}

A cohort of consecutive patients undergoing monosegmental fusion with PLIF between 24th January 2011 and the 14th August 2014, underwent radiological assessment to quantify lordosis change in relation to radiological assessment of cage parameters and position.

\section{Surgical technique}

The indications for monosegmental PLIF reconstruction were degenerative spondylolisthesis, low-grade isthmic spondylolisthesis, degenerative disc disease, foraminal stenosis, post-discectomy back pain, and recurrent disc herniation. Multi-level and revision fusion operations were excluded. The surgical technique included positioning the patient prone on a radiolucent four post-spinal frame with the hips and knees extended. A posterior midline approach allowed the display of the transverse processes. Bilateral total facetectomy was performed and the disc space was prepared, leaving a peripheral ring of annulus. The cartilage endplate was removed with ring curettes with care taken not to disturb the bone endplate. The final decompression included the resection of the ligamentum flavum and part of the adjacent laminae and spinous processes. This latter step completed a posterior column osteotomy and allowed the dorsal compression of the construct without any bone impingement. The extent of the bone resection can be seen when Figs. 1 and 2 are compared. Pedicle screws were placed using anatomical landmarks with radiological assistance. The initial rod placement with distraction allowed the final disc space preparation, distraction, and insertion of the paired lordotic PEEK cages/spacers looking to achieve the maximum height. Insertion of the cages used an 'insert and rotate' $\left(90^{\circ}\right)$ maneuver to obtain optimum cage position [7, 10, 11, 19]. Two types of PEEK cages (spacers) were used: the R90/Hourglass (Medtronic, Minneapolis, MN, USA) and the CoRoent (NuVasive, San Diego, CA, USA). Iliac crest bone graft was inserted between and lateral to the interbody cages for interbody fusion. The screws were then compressed on the rods dorsally to optimize lordotic reconstruction. Further decortication and bone grafting, using local bone derived from the facets and lamina inserted into the posterolateral gutter, completed the posterolateral fusion.

\section{Radiological study}

Pre- and post-operative erect lateral radiographs of 83 patients undergoing monosegmental reconstruction with fusion in the lumbar spine were examined.

On each radiographic set, the pre-operative lordosis and post-operative lordosis were measured at the instrumented segment (Fig. 1) and the key finding was the lordosis change measured in degrees, where a positive value indicated an increase in the monosegmental lordosis. The post-operative radiographs were taken on days 3-5 prior to patient discharge (immediate post-op) and also at 1 year follow-up.

All of the measurements were made on a PACS system (InteleViewer by Intelerad, version 4-6-1-P160, Montreal,

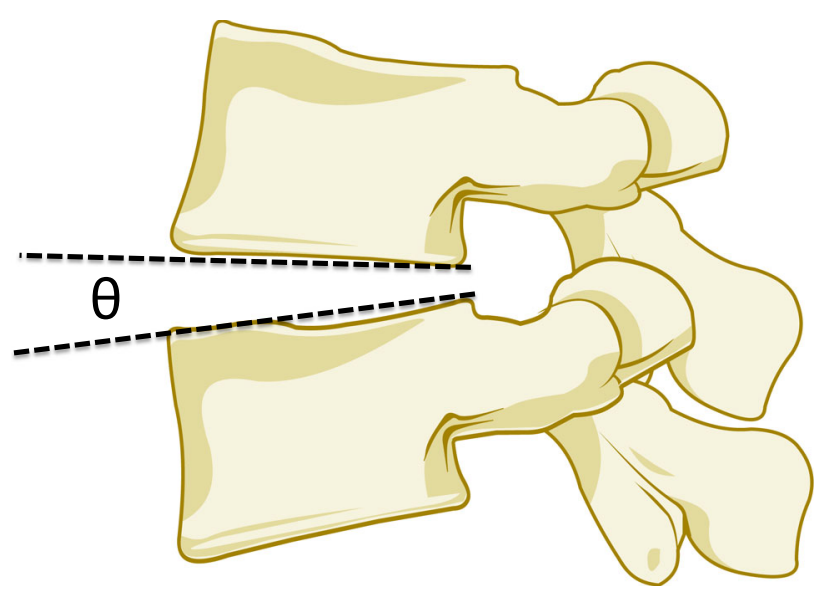

Fig. 1 Measurement of monosegmental lordosis 


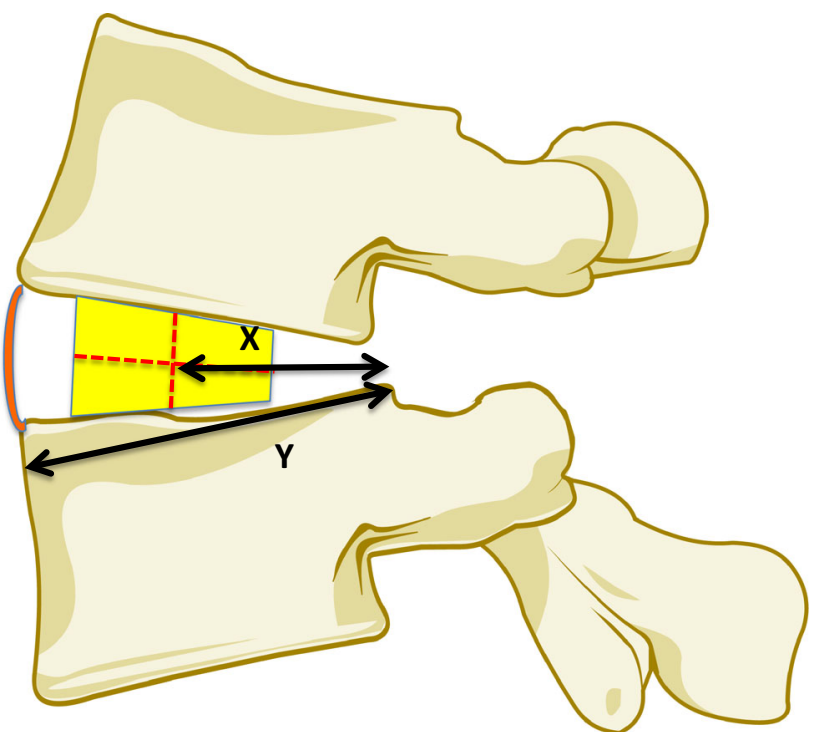

Fig. 2 Measurement of centre point ratio $(X / Y)$

Canada). They were made by a single measurer. Repeated studies were performed for intra-observer variability.

The position of the paired lordotic PEEK cages within the disc space was then studied. All cages used incorporated metallic markers that indicated the cage position, and with the knowledge of the manufacturers' positioning of the markers within the cage, the anterior and posterior extent of each cage could be determined within the disc space. We then calculated the position of the mid-sagittal point of the paired cages, which defined the relationship between the cages and the disc space. We calculated the 'centre point ratio' (or CPR), a ratio of the distance between the midpoint of the cages (from the anterior wall of the more anterior cage to the posterior wall of the more posterior cage) and the posterior extent of the superior endplate of the inferior vertebra DIVIDED by the length of the superior endplate of the inferior vertebra (Fig. 2). This ratio would lead to a perfectly paired centrally placed cage pair having a centre point ratio of 0.5 . Values less that 0.5 would indicate cages placed more in the posterior portion of the disc space, while values greater than 0.5 would indicate more anterior placement. We anticipated clustering of the CPR around 0.5, indicating central placement. While values towards zero or one would be possible, this would represent extreme positioning and, as the ratio relates to the centre of the cages, would require partial overhang of the cage out of the disc space either anteriorly or posteriorly.

We also recorded the distance from the posterior wall of the most posterior cage to the posterior extent of the superior endplate of the inferior vertebra. This was then divided by the length of the superior endplate of the inferior vertebra to give the 'posterior gap ratio' (or PGR) (Fig. 3). This ratio indicated not only cage position (the

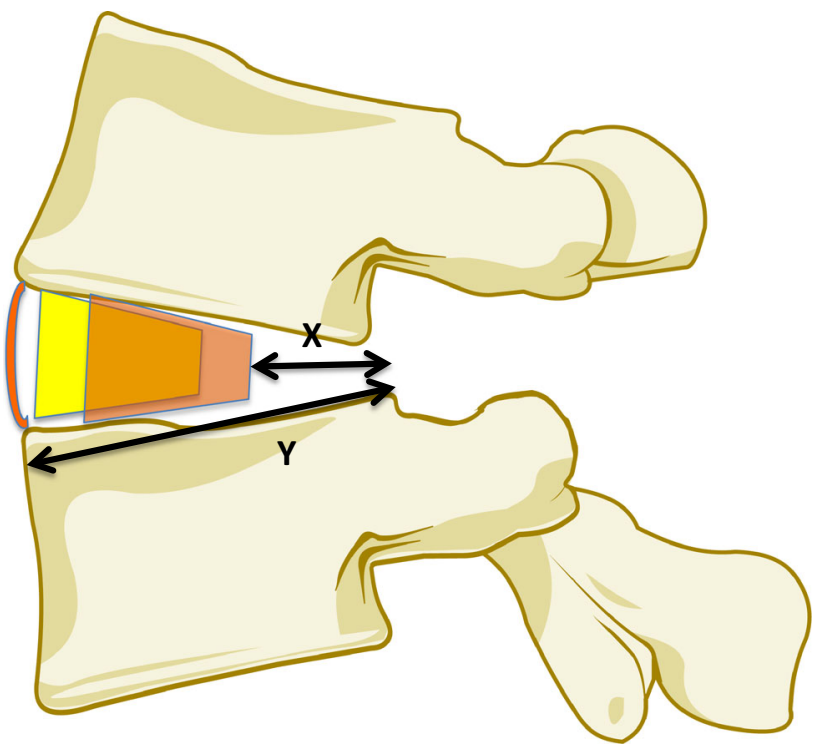

Fig. 3 Measurement of posterior gap ratio $(X / Y)$

larger the ratio, the further forward the cages), but was also an indirect measure of cage length. Two cages placed with little overlap on the lateral view would in effect create one long cage within the disc space, and would result in a smaller posterior gap ratio (Fig. 3).

The patients were clinically assessed prior to surgery and at 1 year follow-up using a pain score (Numeric Rating Scale), the Lower Back Outcome Score (LBOS) [23], and the Roland Morris Disability Questionnaire [24].

The final analysis related the change in lordosis to the following parameters: cage position as determined by CPR and PGR, anterior cage height, cage lordosis as per manufacturer, and cage length (front-to-back dimension). Further analysis examined the final lordosis in relation to the manufacturer's lordosis in the cage.

All statistical tests were performed using SPSS, version 21 (IBM Corp., Armonk, NY). Correlation between change in lordosis and cage placement and size parameters was assessed using the Pearson correlation coefficient. A paired $t$ test was used to compare the mean lordosis achieved by make of cage and the pre- and post-op clinical scores. The intra-observer reliability of the radiographic measurements was evaluated from the intraclass correlation coefficient (ICC).

The study was performed with the approval of the regional ethical committee.

\section{Results}

Eighty-three consecutive single-level PLIF patients were examined. The mean patient age at the time of surgery was 55 years and 6 months. Demographic information and the 
Table 1 Demographic details and implant information for the patient cohort

\begin{tabular}{lc}
\hline Patients & Numbers \\
\hline Total & 83 \\
Male & 38 \\
Female & 45 \\
Diagnoses & \\
Degenerative spondylolisthesis & 28 \\
Isthmic spondylolisthesis & 10 \\
Degenerative disc disease & 21 \\
Foraminal stenosis & 9 \\
Post-discectomy lower back pain & 12 \\
Recurrent disc herniation & 3 \\
Cage implant manufacturer & \\
Medtronic R90 & 53 \\
NuVasive CoRoent & 30 \\
\hline
\end{tabular}

choice of implant are shown in Table 1. The lordotic cage/ spacers varied in length from 20 to $27 \mathrm{~mm}$, and the manufacturers' lordosis for the cage ranged from $10^{\circ}$ to $18^{\circ}$. The anterior cage heights varied from 10 to $17 \mathrm{~mm}$.

The pre- and post-operative lordosis values as per the operated level and the ratios relating to cage position are given in Tables 2 and 3. The overall mean lordosis gain with surgery was $5.98^{\circ}\left(\mathrm{SD} 6.86^{\circ}\right)$. The overall mean cage position was 0.54 as determined by the CPR and 0.16 by the PGR. The findings at 1 year follow-up were maintained: lordosis gain $5.68^{\circ}\left(\mathrm{SD} 7.00^{\circ}\right)$, CPR 0.54, PGR 0.14 . Cage subsidence was not detected on any of the 1 year follow-up radiographs. Not all cages were placed perfectly symmetrically when viewed in the lateral projection. Asymmetric cage placement was assessed by the overlap of the cages and was indicated by an increase in the total front-to-back dimension of the paired cages compared to the length of an individual cage. The mean increase in cage length due to asymmetric placement was $14 \%$. The radiographic measurement technique was reproducible with ICCs ranging from 0.799 to 0.926 for the different radiographic parameters measured.

The CPR was significantly related to the lordosis gain at surgery $\left(r=0.597, r^{2}=0.356, p<0.001\right.$, Fig. 4$)$. The PGR was also significantly correlated with lordosis gain $\left(r=0.537, r^{2}=0.288, p<0.001\right.$, Fig. 5). These correlations with lordosis gain were maintained at 1 year follow-up (CPR: $r=0.624, r^{2}=0.389, p<0.001$, and PGR: $r=0.525, r^{2}=0.276, p<0.001$, respectively).

With regard to cage parameters, a greater anterior cage height was negatively correlated with a change in lordosis $\left(r=-0.297, r^{2}=0.088, p<0.01\right.$, Fig. 6). There was a significant relationship between the manufacturers' cage lordosis and the final $\operatorname{lordosis}\left(r=0.234, r^{2}=0.054\right.$, $p<0.05$ ), although there was no relationship between manufacturer's cage lordosis and the change in lordosis.

There was no statistically significant relationship between cage length and change in lordosis $(p>0.05)$. There was also no difference between the two cage designs in terms of lordosis change $(p>0.05)$.

Clinical outcomes, as assessed by the NRS pain score, LBOS and Roland Morris Disability Questionnaire showed significant improvements following surgery and are detailed in Table 4.

\section{Discussion}

This study has demonstrated that cage position, size and shape, as well as surgical technique determine lordosis during PLIF surgery. Placement of the paired cages should be relatively anterior within the disc space to optimize the lordosis gain. When the sagittal midpoint of the cages is anterior to the midpoint of the disc, as determined by the 'centre point ratio', the increase in lordosis at the level of reconstruction is optimized. Examples of this can be seen in Figs. 7 and 8.

This study is the first to demonstrate that more anterior cage placement results in greater intervertebral lordosis. Previous studies have produced varying recommendations for intervertebral cage placement. The initial advice for transforaminal lumbar interbody fusion (TLIF) was to place the intervertebral cage in the middle/posterior third of the disc space [25]. Posterolateral placement within the intervertebral space, where the endplate is thicker [8] and stronger $[8,26]$, has been suggested following a biomechanical study assessing the risk of cage subsidence [14], whereas central placement has shown greater subsidence in a clinical study [15]. With regard to anterior placement, both a cadaveric [27] and a clinical study [28] involving TLIF found no difference in intervertebral lordosis when cages were placed in the anterior half of the disc space. However, the surgical technique in both studies did not involve bilateral total facetectomies and excision of adjacent spinous processes, nor did they aim for extreme anterior placement, so this may have limited the final lordosis achieved.

The results of this study suggest that the principles of osteotomy correction about a centre of rotation are applicable to the PLIF surgical technique. The wide posterior resection of the facets and partial resection of the laminae and spinous processes facilitate eventual dorsal closure with lordosis improvement. The disc space preparation with disc space distraction achieves anterior distraction, although in general, the intact anterior longitudinal ligament, which acts as a tether, limits this. The further anterior the paired cages can be placed within the disc space, then 
Table 2 Pre- and post-operative (immediate) lordosis values for each treatment level

\begin{tabular}{|c|c|c|c|c|c|c|c|}
\hline \multirow[t]{2}{*}{ Level } & \multirow[t]{2}{*}{$N$} & \multirow{2}{*}{$\begin{array}{l}\text { Mean centre point ratio (CPR) } \\
\text { immediate post-op }\end{array}$} & \multirow{2}{*}{$\begin{array}{l}\text { Mean posterior gap ratio } \\
\text { (PGR) immediate post-op }\end{array}$} & \multicolumn{4}{|c|}{ Mean monosegmental lordosis (STD) } \\
\hline & & & & Pre-op & $\begin{array}{l}\text { Post-op } \\
\text { (immediate) }\end{array}$ & Normal [12] & $\begin{array}{l}\text { Change from } \\
\text { pre-op }\end{array}$ \\
\hline $\mathrm{L} 3 / 4$ & 8 & 0.45 & 0.06 & $7.46^{\circ}\left(4.76^{\circ}\right)$ & $6.90^{\circ}\left(5.54^{\circ}\right)$ & $9.25^{\circ}\left(2.54^{\circ}\right)$ & $-0.57^{\circ}\left(4.44^{\circ}\right)$ \\
\hline $\mathrm{L} 4 / 5$ & 42 & 0.54 & 0.15 & $7.30^{\circ}\left(5.20^{\circ}\right)$ & $12.83^{\circ}\left(5.61^{\circ}\right)$ & $12.29^{\circ}\left(3.34^{\circ}\right)$ & $5.53^{\circ}\left(5.90^{\circ}\right)$ \\
\hline $\mathrm{L} 5 / \mathrm{S} 1$ & 33 & 0.56 & 0.20 & $8.42^{\circ}\left(6.24^{\circ}\right)$ & $16.55^{\circ}\left(5.41^{\circ}\right)$ & $15.58^{\circ}\left(5.43^{\circ}\right)$ & $8.14^{\circ}\left(7.40^{\circ}\right)$ \\
\hline Total & 83 & 0.54 & 0.16 & & & & \\
\hline
\end{tabular}

Table 3 Pre- and post-operative (1 year) lordosis values for each treatment level

\begin{tabular}{|c|c|c|c|c|c|c|c|}
\hline \multirow[t]{2}{*}{ Level } & \multirow[t]{2}{*}{$N$} & \multirow{2}{*}{$\begin{array}{l}\text { Mean centre point ratio }(\mathrm{CPR}) \\
1 \text { year post-op }\end{array}$} & \multirow{2}{*}{$\begin{array}{l}\text { Mean posterior gap ratio } \\
\text { (PGR) } 1 \text { year post-op }\end{array}$} & \multicolumn{4}{|c|}{ Mean monosegmental lordosis (STD) } \\
\hline & & & & Pre-op & $\begin{array}{l}\text { Post-op } \\
\text { (1 year) }\end{array}$ & Normal [12] & $\begin{array}{l}\text { Change from } \\
\text { pre-op }\end{array}$ \\
\hline $\mathrm{L} 3 / 4$ & 8 & 0.45 & 0.05 & $7.46^{\circ}\left(4.76^{\circ}\right)$ & $6.78^{\circ}\left(4.97^{\circ}\right)$ & $9.25^{\circ}\left(2.54^{\circ}\right)$ & $-0.68^{\circ}\left(4.10^{\circ}\right)$ \\
\hline $\mathrm{L} 4 / 5$ & 42 & 0.53 & 0.12 & $7.30^{\circ}\left(5.20^{\circ}\right)$ & $12.81^{\circ}\left(5.61^{\circ}\right)$ & $12.29^{\circ}\left(3.34^{\circ}\right)$ & $5.52^{\circ}\left(6.30^{\circ}\right)$ \\
\hline $\mathrm{L} 5 / \mathrm{S} 1$ & 32 & 0.55 & 0.19 & $8.42^{\circ}\left(6.24^{\circ}\right)$ & $16.01^{\circ}\left(4.54^{\circ}\right)$ & $15.58^{\circ}\left(5.43^{\circ}\right)$ & $7.49^{\circ}\left(7.63^{\circ}\right)$ \\
\hline Total & 82 & 0.53 & 0.14 & & & & \\
\hline
\end{tabular}

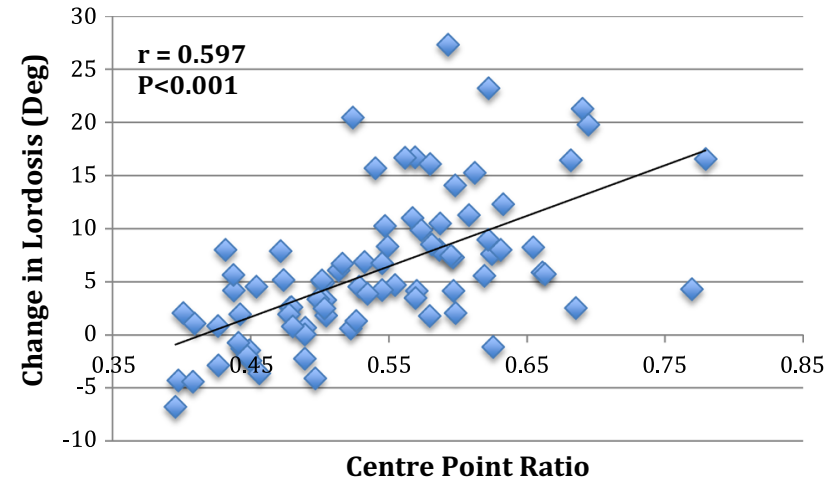

Fig. 4 Relationship between centre point ratio and change in lordosis

the further anterior the centre of rotation about which the deformity correction occurs. Thus, lordosis gain is increased with relative anterior position of the cages, and increased posterior gap behind the cages where compression can occur.

Failure to widely decompress and osteotomise at the levels of the facets and spinous processes posteriorly likely explains the lack of lordosis gain in lateral lumbar interbody fusion and transforaminal lumbar interbody fusion with unilateral facetectomy $[5,7,10,16-18,29,30]$. Conversely, if wide decompression and bilateral facetectomy are performed, then meaningful lordosis gain can be

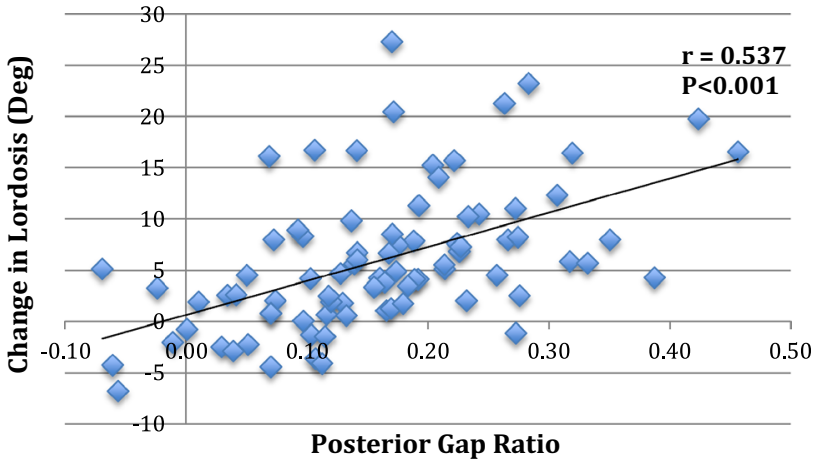

Fig. 5 Relationship between posterior gap ratio and change in lordosis

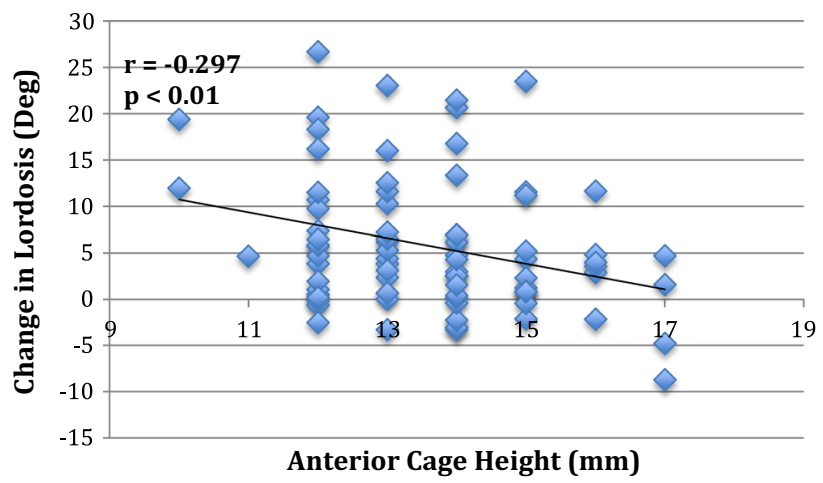

Fig. 6 Relationship between anterior cage height and change in lordosis 
Table 4 Mean clinical outcome scores pre- and post-op

\begin{tabular}{llccc}
\hline & $N$ & Pre-op & Post-op (1 year) & $P$ \\
\hline Pain score (NRS) & 76 & 6 & 2 & 0.004 \\
Roland Morris Disability Questionnaire & 74 & 15 & 10 & 0.02 \\
Low Back Outcome Score (LBOS) & 75 & 30 & 52 & $<0.001$ \\
\hline
\end{tabular}
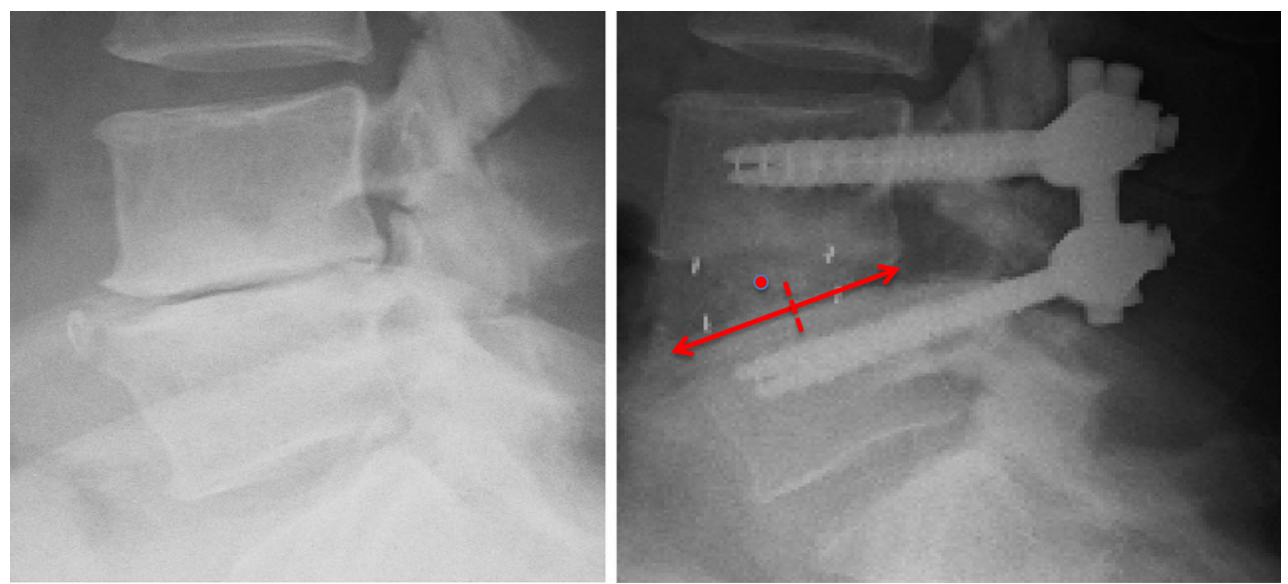

Fig. 7 Pre- and post-operative radiographs showing anteriorly placed cages. The red dot indicates the midpoint of the cages. The dashed line indicates the midpoint of the endplate. Centre point ratio 0.56 , lordosis change $+12.52^{\circ}$
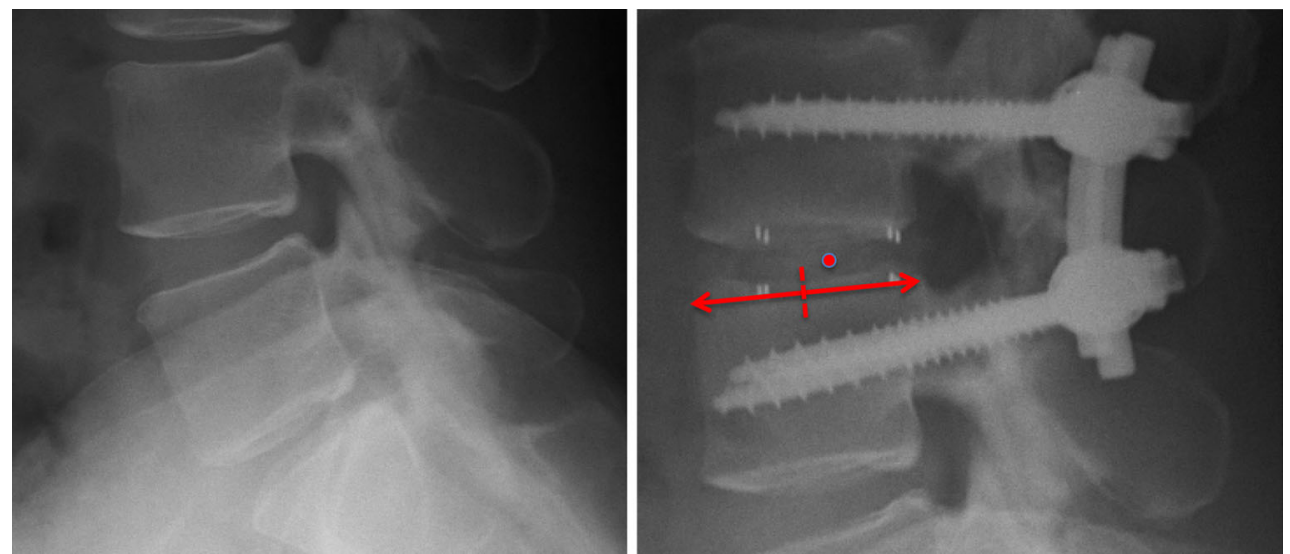

Fig. 8 Pre- and post-operative radiographs showing posteriorly placed cages. The red dot indicates the midpoint of the cages. The dashed line indicates the midpoint of the endplate. Centre point ratio 0.40 , lordosis change $-2.5^{\circ}$

achieved with TLIF [31], which is comparable to the lordosis gain seen in this study.

An obvious concern with techniques that partially resect and osteotomise the posterior structures to allow dorsal compression is that inadvertent foraminal narrowing may occur. This seems not to be a clinical problem both due to the height gain anteriorly with the paired cages prior to dorsal compression and the wide decompression of the foramen with the total facetectomy.

With regard to cage shape, it has been shown that lordotic 'wedged' cages or structural allograft results in greater monosegmental lordosis than non-wedged cages
[15, 32-35]. However, the effect of other cage parameters such as cage height and length has not been previously assessed.

The negative correlation seen with anterior cage height can be explained by several mechanisms. With a tall cage, an intact ALL may act as a tether and restrict dorsal compression, with less resulting lordosis. Alternatively, the tethering 'resistance' of the intact ALL may lead to endplate fracture and cage subsidence, reducing lordosis gain. Finally, an excessively tall cage, with its maximum height at the anterior aspect of the cage, may migrate to the tallest dimension within the expanded disc space-the midpoint of the disc in 
the sagittal view, where the concave elliptical endplates are most distant. This would have the effect of placing the cage more posteriorly giving a much lower CPR, restricting posterior compression, and reducing lordosis.

There was no correlation between cage length and final lordosis. It could be argued that there should be a negative correlation, because as the cages become longer, they become less effective fulcrums/pivots and it becomes harder to lordose the segment by applying compression along the rods. This was not seen and may be due to small sample size, the limited number of different lengths used, and the small variation in lengths (longest $27 \mathrm{~mm}$, shortest $20 \mathrm{~mm}$ ). However, the posterior gap ratio can be considered an indirect marker of cage length. The significant correlation seen between increasing posterior gap ratio and lordosis gain again emphasizes not only the importance of anterior placement, but also not using too long a cage.

This study has demonstrated a strong correlation between the cage lordosis and the final lordosis. Given the significant lordosis gain at both L4/5 and L5/S1, a gain that is much greater than many of the published changes in lordosis for TLIF surgery, the study strongly suggests that it is the combination of the extensive posterior facetectomy and decompression and the anterior cage placement that is required to achieve the lordosis built into the implant.

This study has both strengths and weaknesses. The strengths of the study included a consistent surgical technique with a single surgeon series and in particular a consistent technique of posterior decompression, facetectomy, and spinous process resection/osteotomy. The assessment of the imaging was assisted with a rigorous imaging protocol and the measurement techniques were highly repeatable. Lateral radiographs were taken according to a set protocol with a consistent standing position relative to the $\mathrm{X}$-ray source. There was only a single patient who was lost to follow-up at 1 year.

The longer term success of this operation is dependent on fusion occurring so that the restoration of lordosis is preserved. The follow up period of one year may not fully confirm fusion, but clearly indicates lordosis is maintained over this period in these uni-segmental fusions. Whilst construct failure occurs later in long constructs, many nonunions are clearly symptomatic at the one-year mark. We have not seen later loss of lordosis in this or similar groups of patients, but acknowledge that later changes could occur.

There is no attempt to relate lordosis gain to improved patient-related outcomes, yet this relationship is established in the literature $[5,7,10,19]$. Long-term follow-up would be required to confirm reduced adjacent segment degeneration with improved monosegmental lordosis. However, good clinical outcome scores have been demonstrated in this patient cohort.
The study is 'uncontrolled' in that it does not represent a randomized use of cage lordosis or cage height. The cages were skewed towards greater height and lordosis due to the surgical aim, at that time, of maximizing these parameters within the disc, and this was generally determined by the intraoperative anatomy and surgical findings.

Although significant relationships have been demonstrated, there is some variation in the magnitude of the correlation coefficients ( $r$ values). The strongest relationship is between CPR and lordosis gain at 1 year, and has an $r$ value of 0.624 suggesting a "strong" correlation. Other correlations with smaller $r$ values are moderate to weak [36]. However, this interpretation is arbitrary [37] and the uncontrolled nature of this retrospective study must be considered with multiple patient, implant, and surgical factors contributing to the overall measured lordosis. Nevertheless, the coefficient of determination $\left(r^{2}\right)$ indicates that the CPR can explain almost $40 \%$ of the variation in lordosis achieved following surgery.

In conclusion, this study strongly suggests that surgical technique with wide posterior osteotomy and relative anterior placement of the cage within the disc space is the optimal method to maximize lordosis gain with a monosegmental reconstruction and fusion using PLIF techniques. The cage chosen should also be of moderate length-short enough to enable posterior compression, and of moderate height- to prevent overstuffing of the disc space.

\section{Compliance with ethical standards}

Conflict of interest All authors declared that they have no potential conflict of interest.

Funding This research has not received any funding.

Open Access This article is distributed under the terms of the Creative Commons Attribution 4.0 International License (http://crea tivecommons.org/licenses/by/4.0/), which permits unrestricted use, distribution, and reproduction in any medium, provided you give appropriate credit to the original author(s) and the source, provide a link to the Creative Commons license, and indicate if changes were made.

\section{References}

1. Roussouly P, Gollogly S, Berthonnaud E, Dimnet J (2005) Classification of the normal variation in the sagittal alignment of the human lumbar spine and pelvis in the standing position. Spine 30:346-353

2. Smith JS, Klineberg E, Schwab F et al (2013) Change in classification grade by the SRS-Schwab Adult Spinal Deformity Classification predicts impact on health-related quality of life measures: prospective analysis of operative and nonoperative treatment. Spine 38:1663-1671. doi:10.1097/BRS.0b013e31829ec563

3. Schwab F, Ungar B, Blondel B et al (2012) Scoliosis Research Society-Schwab adult spinal deformity classification: a validation 
study. Spine 37:1077-1082. doi:10.1097/BRS. 0b013e31823e15e2

4. Nakashima H, Kawakami N, Tsuji T et al (2015) Adjacent segment disease after posterior lumbar interbody fusion: based on cases with a minimum of 10 years of follow-up. Spine 40:E831E841. doi:10.1097/BRS.0000000000000917

5. Bourghli A, Aunoble S, Reebye O, Le Huec JC (2011) Correlation of clinical outcome and spinopelvic sagittal alignment after surgical treatment of low-grade isthmic spondylolisthesis. Eur Spine J 20(suppl 5):663-668. doi:10.1007/s00586-011-1934-z

6. Vialle R, Dauzac C, Khouri N et al (2007) Sacral and lumbarpelvic morphology in high-grade spondylolisthesis. Orthopedics 30:642-649

7. Kawakami M, Tamaki T, Ando M et al (2002) Lumbar sagittal balance influences the clinical outcome after decompression and posterolateral spinal fusion for degenerative lumbar spondylolisthesis. Spine 27:59-64

8. Lowe TG, Hashim S, Wilson LA et al (2004) A biomechanical study of regional endplate strength and cage morphology as it relates to structural interbody support. Spine 29:2389-2394

9. Rothenfluh DA, Mueller DA, Rothenfluh E, Min K (2015) Pelvic incidence-lumbar lordosis mismatch predisposes to adjacent segment disease after lumbar spinal fusion. Eur Spine J 24:1251-1258. doi:10.1007/s00586-014-3454-0

10. Lazennec JY, Ramaré S, Arafati N et al (2000) Sagittal alignment in lumbosacral fusion: relations between radiological parameters and pain. Eur Spine J 9:47-55

11. Shin M-H, Ryu K-S, Hur J-W et al (2013) Comparative study of lumbopelvic sagittal alignment between patients with and without sacroiliac joint pain after lumbar interbody fusion. Spine 38:E1334-E1341. doi:10.1097/BRS.0b013e3182a0da47

12. Damasceno LHF, Catarin SRG, Campos AD, Defino HLA (2006) Lumbar lordosis: a study of angle values and of vertebral bodies and intervertebral discs role. Acta Ortop Bras 14:193-198

13. Kumar MN, Baklanov A, Chopin D (2001) Correlation between sagittal plane changes and adjacent segment degeneration following lumbar spine fusion. Eur Spine J 10:314-319

14. Labrom RD, Tan J-S, Reilly CW et al (2005) The effect of interbody cage positioning on lumbosacral vertebral endplate failure in compression. Spine 30:E556-E561

15. Abbushi A, Cabraja M, Thomale U-W et al (2009) The influence of cage positioning and cage type on cage migration and fusion rates in patients with monosegmental posterior lumbar interbody fusion and posterior fixation. Eur Spine J 18:1621-1628. doi:10. 1007/s00586-009-1036-3

16. Watkins RG IV, Hanna R, Chang D, Watkins RG III (2014) Sagittal alignment after lumbar interbody fusion. J Spinal Disord Tech 27:253-256. doi:10.1097/BSD.0b013e31828a8447

17. Hsieh PC, Koski TR, O'Shaughnessy BA et al (2007) Anterior lumbar interbody fusion in comparison with transforaminal lumbar interbody fusion: implications for the restoration of foraminal height, local disc angle, lumbar lordosis, and sagittal balance. J Neurosurg Spine 7:379-386. doi:10.3171/SPI-07/10/ 379

18. Kim J-S, Kang BU, Lee S-H et al (2009) Mini-transforaminal lumbar interbody fusion versus anterior lumbar interbody fusion augmented by percutaneous pedicle screw fixation: a comparison of surgical outcomes in adult low-grade isthmic spondylolisthesis. J Spinal Disord Tech 22:114-121. doi:10.1097/BSD. 0b013e318169bff5

19. Sears W (2005) Posterior lumbar interbody fusion for degenerative spondylolisthesis: restoration of sagittal balance using insertand-rotate interbody spacers. Spine J 5:170-179. doi:10.1016/j. spinee.2004.05.257

20. Yang E-Z, Xu J-G, Liu X-K et al (2016) An RCT study comparing the clinical and radiological outcomes with the use of
PLIF or TLIF after instrumented reduction in adult isthmic spondylolisthesis. Eur Spine J 25:1587-1594. doi:10.1007/ s00586-015-4341-z

21. Mummaneni PV, Dhall SS, Eck JC et al (2014) Guideline update for the performance of fusion procedures for degenerative disease of the lumbar spine. Part 11: interbody techniques for lumbar fusion. J Neurosurg Spine 21:67-74. doi:10.3171/2014.4. SPINE14276

22. Zhang Q, Yuan Z, Zhou M et al (2014) A comparison of posterior lumbar interbody fusion and transforaminal lumbar interbody fusion: a literature review and meta-analysis. BMC Musculoskelet Disord 15:367. doi:10.1186/1471-2474-15-367

23. Greenough CG, Fraser RD (1992) Assessment of outcome in patients with low-back pain. Spine 17:36-41

24. Roland M, Morris R (1983) A study of the natural history of back pain. Part I: development of a reliable and sensitive measure of disability in low-back pain. Spine 8:141-144

25. Harms JG, Jeszenszky D (1998) The unilateral transforaminal approach for posterior lumbar interbody fusion. Oper Orthop Traumatol 10:90-102. doi:10.1007/s00064-006-0112-7

26. Grant JP, Oxland TR, Dvorak MF (2001) Mapping the structural properties of the lumbosacral vertebral endplates. Spine 26:889-896

27. Faundez AA, Mehbod AA, Wu C et al (2008) Position of interbody spacer in transforaminal lumbar interbody fusion: effect on 3-dimensional stability and sagittal lumbar contour. J Spinal Disord Tech 21:175-180. doi:10.1097/BSD.0b013e318074bb7d

28. Kepler CK, Rihn JA, Radcliff KE et al (2012) Restoration of lordosis and disk height after single-level transforaminal lumbar interbody fusion. Orthop Surg 4:15-20. doi:10.1111/j.1757-7861. 2011.00165.x

29. Acosta FL, Liu J, Slimack N et al (2011) Changes in coronal and sagittal plane alignment following minimally invasive direct lateral interbody fusion for the treatment of degenerative lumbar disease in adults: a radiographic study. J Neurosurg Spine 15:92-96. doi:10.3171/2011.3.SPINE10425

30. Sharma AK, Kepler CK, Girardi FP et al (2011) Lateral lumbar interbody fusion: clinical and radiographic outcomes at 1 year: a preliminary report. J Spinal Disord Tech 24:242-250. doi:10. 1097/BSD.0b013e3181ecf995

31. Jagannathan J, Sansur CA, Oskouian RJ et al. (2009) Radiographic restoration of lumbar alignment after transforaminal lumbar interbody fusion. Neurosurgery 64:955-963. doi:10.1227/ 01.NEU.0000343544.77456.46

32. Gödde S, Fritsch E, Dienst M, Kohn D (2003) Influence of cage geometry on sagittal alignment in instrumented posterior lumbar interbody fusion. Spine 28:1693-1699. doi:10.1097/01.BRS. 0000083167.78853.D5

33. Takahashi H, Suguro T, Yokoyama Y et al (2010) Effect of cage geometry on sagittal alignment after posterior lumbar interbody fusion for degenerative disc disease. J Orthop Surg (Hong Kong) 18:139-142

34. Groth AT, Kuklo TR, Klemme WR et al (2005) Comparison of sagittal contour and posterior disc height following interbody fusion: threaded cylindrical cages versus structural allograft versus vertical cages. J Spinal Disord Tech 18:332-336

35. Diedrich O, Perlick L, Schmitt O, Kraft CN (2001) Radiographic spinal profile changes induced by cage design after posterior lumbar interbody fusion preliminary report of a study with wedged implants. Spine 26:E274-E280

36. Evans JD (1996) Straightforward statistics for the behavioral sciences. Brooks/Cole, Pacific Grove

37. Cohen J (1988) Statistical power analysis for the behavioral sciences. Lawrence Erlbaum Associates, Mahwah 